\title{
Analysis on the Teaching Mode of College English Teachers' Turnover
}

\author{
Li Meijing \\ Foreign Language Department \\ Jilin Business and Technology College \\ Changchun, China \\ 182076127@qq.com
}

\begin{abstract}
A new type of teaching organization, which is not only suitable for primary and secondary school teaching, but also can be used in the teaching of University. The flipped classroom relevant concepts and contents and characteristics were analyzed in the course of the study, analysis the relationship between the flipped classroom and College English, and bring forward the flipped classroom in university teaching in the application of basic teaching process, analysis of the specific operation of the relevant matters needing attention.
\end{abstract}

Keywords_Flip the classroom; university teaching; Application Research

With the development of information technology, online teaching resources are becoming more and more abundant. In recent years, the flipped classroom has become a hot topic in educational circles[1]. Classroom flip upside down the traditional learning process, students in front of the class through online video teaching resources based knowledge of the focus and difficulty of autonomous learning, teachers are no longer used classroom time to explain the concept of knowledge, but through the organization of various tasks of activities to promote students' Internalization of knowledge. The theory of flipped classroom model can greatly enhance the performance of course, but the course effect involves a series of curriculum design and implementation issues. College English curriculum emphasis on language skills training, flipping the classroom teaching mode is suitable for such courses? These questions can only be answered by teaching practice.

\section{Flipped Classroom Literature REVIEW}

The so-called flipped classroom is in the information environment, teachers provide a teaching video as the main form of learning resources, video teaching learning resources to watching and learning from the students completed before class, teachers and students in the classroom together to complete homework and answering, collaborative inquiry and interactive communication activities of a new teaching mode. Some scholars believe that the core of the teaching video is not flipped classroom, the subversion of the traditional teaching process and based on "take the student as the center" thinking is the true meaning of the flipped classroom, flipped classroom success thanks to explore learning and project based learning of active learning[2]. Foreign flipped classroom study focused on the flipped classroom use in teaching practice, and the traditional teaching mode, the comparative study and exploration of the flipped classroom and other teaching method or the technology combining the application effect of. Research in foreign countries mainly focuses on the development of learning resources, such as video, and the related research on the implementation steps of the flipped classroom. In some areas of foreign countries, several years of flipped classroom teaching experiments have been carried out, the relatively mature, and formed a number of fixed models. Accumulated a number of research and practice experience, but still relatively fragmented, lack of the connotation of the flipped classroom, characteristics, elements and advantages and disadvantages of such a systematic summary.

The research and practice of the flipped classroom has just started, is still in the introduction stage, only the individual school carried out the flipped classroom teaching experiment, such as Jukui middle school in Chongqing and Guangzhou Haizhu District No. 5 middle school. At the same time, it also has a preliminary exploration of the flipped classroom teaching mode, and the research on the teaching design based on flipped classroom concept in the information environment. Overall, the domestic turnover of the literature in the classroom, the introduction of more than research, theoretical analysis more than practical applications, and more concentrated in primary and secondary school classroom teaching, involving the application of college teaching research is less[3]. The flipped classroom teaching process is "students see in advance materials -- do the exercises, teachers guide, summed to enhance, the flow and the traditional classroom" preview, lectures -- Practice "in the design and teaching organization is quite different, as can be seen from the flipped classroom of the existing research.

Development of technology led to the change in information dissemination, and a direct impact on the change in the field of education is to flip the classroom appears. The late 1990s, with the "Blackboard" "Moodle" Rise and other network teaching platform, teachers began to slide (PPT) files into other courses content network altar extracurricular learning to use, and gradually formed a "courseware" " online courses "and so on. With online courses technology matures, richer content, teaching the use of online resources is increasing. 
Subsequently, the mixed teaching (blended learning / hybrid learning) concept appears. Taught many

Further exploration division, trying to maximize the use of online resources functions, network resources and classroom learning combined. The most obvious difference between the flipped classroom and students to preview the traditional sense is IT intervention. Bishop \& Verleger (2013) to define a flipped classroom teaching skills for the next class on group learning activities and interactive lessons based on individualized teaching computer combination. Flipped classroom with traditional classroom lectures and the difference lies not only in time and space to exchange homework, but also in teaching activities and the rational design of spatial and temporal distribution. In the flipped classroom, enter the complete autonomy of knowledge by the IT extracurricular assist learners, and classroom is used to focus on interpersonal interactions output type.

\section{FLIPPED CLASSROOM AND COLLEGE ENGLISH}

Flipped classroom with multimedia technologies widely development arises at the historic moment, due to the students of computer, network, information technology and other new things have natural affection. Therefore the flipped classroom application in College English classroom is bound by students welcome. Turn the classroom first so that students can share the latest knowledge resources through video. Once again, it has reconstructed the structure and the way of traditional teaching. At present, one of the difficult problems in College English class is the limited class hours and the teaching content[5]. However, the improvement of students' language ability can't be separated from a large number of listening and speaking training and interactive communication between teachers and students. Most colleges and universities have only four classes per week. In the limited class, the teachers have to complete the teaching tasks and achieve the teaching goals. In the past, teachers do not have enough time to design teaching activities, which can't be personalized to students. Flipped classroom use of the teacher is freed from the classroom to explain that students use extra-curricular time to watch the video teaching, classroom time can be used to organize various teaching activities, to help students improve the ability to use language. Therefore, the teacher's role changed completely, from the center of the classroom change into the classroom activities of the organizers, director, supervisor, coordination, evaluation subjects, and students to the classroom to become the main body, they both classroom participants and learners and author of classroom activities.

People usually think that learning a foreign language is an input to the output of the process, the output of drive input contributed to "on the assumption that the output is the power and purpose of the language acquisition, the input is completed the task outputs to contribute the means (Wen Qiufang, 2014). Students to successfully complete the task of the output of the teacher, you need to seriously study the input material, to get the necessary help. Combination of College English course in general class nervous, the limited classroom time very difficult for both input and output. The development of educational technology enable students in class and outside class English learning possible, let the students not only can be obtained in extra-curricular input help, and can get the output of the trained in class, so ma Wu Lin, Zhang Xiaopeng 2014:57 proposed to carry out the classroom and network based teaching in College English hybrid is to ensure the quality of College English teaching is an important way to the. Hu Jiehui, Wu Zhongjie (2014:42) is that college English Teaching in the form of

To "leveraging the MOOC implementation from input to output to drive the flip", in order to truly "to improve the students' comprehensive ability of using English, make them in the future study, work and social interactions can use English to communicate effectively". Empirical studies from multiple subjects have shown a positive effect on the learning of flipped classroom. Compared with the traditional classroom, classroom flip in improving the flexibility of learning, culture exchanges and coordination ability and to cultivate high-level thinking has obvious effect (Baker, 2000; Strayer, 2012. Ma Xiulin, 2013). This training to improve the students' language proficiency and communicative competence, speculative development ability is of great significance. However, most of the existing research reports on the flipped classroom are mostly science and engineering courses. College English curriculum students have basic knowledge of English language, the basic framework; do not need to explain the system. What should be flipped over in the course of College English? How to flip? How to make use of the advantages of the flipped classroom in autonomous learning, cooperative communication and high level thinking, strengthen the development of students' English language ability and thinking ability? With these questions, we conducted a flipped classroom teaching experiment, whose concerns include: (1) whether the College English course students accept the flipped classroom model? (2) what are the factors that influence the development of students' English language proficiency? (3) what is the status of autonomous learning in College English teaching model? (4) what are the views of the students in the College English teaching model?

\section{The Design of COLLEge ENGLish FlipPED ClAssRoOM}

The senior English read and write is one of the advanced language skills courses in College English curriculum system, aims to cultivate student's reading and writing skills and critical thinking skills, this needs through a large number of practical activities to achieve[6]. Therefore we select the course as a foreign language in the flipped classroom experiment course. Flipped classroom and the basic elements of language learning the basic rules based on, we believe that college English flipped classroom design should be based on the following basic understanding: (1) the classroom is a place for students' language use practice; (2) language use practice should be guided by the project, with task as the carrier; (3) on the topic of language, background knowledge, and so on a series of online learning resources is the practice of classroom language support. We choose the PBL based on the concept of the preparation of teaching materials, "New College English integrated course, excellent article". Each unit of the textbook is designed around a practical project, and the unit learning process is the process of using different language materials and language skills to complete the project. Curriculum design and development is divided into 4 stages: 
(1) To establish the output items: according to the theme of the unit and the teaching goal for each unit of the output of the project;

(2) The learning task decomposition project: segmentation output of each unit set up a series of interlocking learning tasks;

(3) The organization of supporting materials: to determine the required skills and knowledge to complete the project, the required materials, according to the needs of the selection, supplement and development;

(4) To generate the implementation of teaching plan: according to the class arrangement of learning tasks and evaluation of the development process.

Curriculum implementation on parting line and line two parts: part of the online mainly solves the project completed the language and culture knowledge input, including video lecture and practice test, also provide practice timely exchange of learning; classroom activities, extracurricular group activity is the main part of the line, for students to provide analysis, synthesis, and evaluation of opportunities to practice. The textbook unit 5 "enhance the integrity" as an example, the project unit to report on the campus integrity, the dismantling project for "preliminary understanding" and "depth" "Analysis on three tasks and each task were involved in online and classroom activities.

(1) a preliminary understanding: students learning teaching materials and online material on American campus integrity learning materials and exam cheating case of news reports, unit theme background knowledge to understand, for honesty campus grouping design questionnaire, to carry out investigation, data collection, and to report the findings in the classroom.

(2) In-depth study: students grouped according to the survey results to discuss the issue of integrity of the campus, the independent reading of the two articles in the textbook. Online platform provides the text to explain the video, explain the language of heavy and difficult, put forward to reflect on the problem, cause students to think, to prepare for the classroom debate. Class, students for both the positive and negative side "my school whether to invigilate" debate, in the debate statements their analysis results, the formation of thinking of the collision.

(3) Analysis and Reflection: students to reflect on the results of the analysis, on the basis of the pre task writing project report, describe the problems existing in the campus integrity, multi angle analysis, identify problems and propose solutions. In the completion of the project, students need to use listening, speaking, reading and writing the skills, language skills training, and analysis, synthesis and evaluation of highlevel thinking ability training, training the thinking ability.

"Flipped classroom" application can produce a good effect in many aspects. Students can arrange the learning progress according to their own learning habits, learning selfmanagement awareness greatly enhanced. Through the network timely feedback teachers can understand the problem of learning difficult students can make more targeted counseling. The time for interaction in the classroom is greatly increased, and the mutual help and reminding of the peer will be improved. The efficiency of learning such a learning process will enable students to improve their performance significantly.

College English Teaching flipped classroom experimental results show this model has been highly recognized by students Flipped classroom model brings a lot of reading and writing exercises, timely feedback and in-depth discussion of the students' language and thinking skills play a better role in promoting development. Students self-learning process, and can't consciously do all the learning task, flipped classroom teaching task design should fully consider the relevance of independent learning and classroom activities. Students also self-learning online teaching materials Personalized put forward higher requirements. Effective classroom activities designed to compensate for the lack of network course, make flipped classroom teaching overall success. Output type of classroom activity interesting, can fully exercise students' language skills, collaboration, communication skills and highlevel thinking skills by students. Based on the group's activities to enhance learning motivation, reduce anxiety, and promote cooperation and exchanges is an effective form of organization of classroom activities. Development of information technology boom triggered a flipped classroom, but the university's English network curriculum should be how to design, production, and how online courses combine classroom entities, it needs to be further explored in practice.

Flipped classroom fundamental advantage is not in the application of technology, and more reflect improvements in technology development have brought the whole teaching pattern. Only the presentation and evaluation of the parties from the target, content, content in the face of English course more in-depth study, to take advantage of the entity class network technology support for college English curriculum redesign in order to better address the college English teaching performance issues.

\section{SUMMARY}

University students have more extra-curricular learning time and more flexible learning schedule compared to middle school students, more conducive to the flipped classroom applications in university. The current college students, the basic conditions have Internet access, but also have the technical ability to operate a network of learning required. It can be said that, from the level of the students, teaching at the university adopted flipped classroom model there is no obstacle. Students learn both autonomous and exploratory, not suitable for a "chalk and talk" to explain the way, on the contrary, college students should be learning self-oriented, so that students get a better development in seminar-style teaching, extra-curricular learning. Flipped classroom is entirely consistent with this teaching philosophy, but also to provide operational solutions and processes for the realization of this concept, has a good prospect in university teaching. 


\section{REFERENCES}

[1] Katie Ash. Educators Evaluate 'Flipped Classrooms' Benefits and drawbacks seen in replacing lectures with on-demand video[J].Education Week, 2012,(10):6-8.

[2] Justin G. Gardner. The Inverted Agricultural Economics Classroom: A new way to teach? A new way to learn? [A] . presentation at the Agricultural \& Applied Economics Association's 2012 AAEA Annual Meeting, Seattle[C]. Washington, 2012:12-14.

[3] Jeremy F. Strayer. How learning in an inverted classroom influences cooperation, innovation and task orientation [J].Learning Environ Res, 2012, (15):171-193.
[4] Gerald C. Cannod, Janet E. Burge, Michael T. Helmick. Using the Inverted Classroom to teach Software Engineering[A]. 2008 ACM/IEEE 30th International Conference on Software Engineering, 2008,:777-786.

[5] B aker, J. W. The "classroom flip": Using web course management tools to become the guide on the side [A]. In Chambers, J. A.(ed). Selected Papers from the 11th International Conference on college teaching and learning [C]. Jacksonville, FL: Florida Community College at Jacksonville, 2000: 9-17.

[6] M cLaughlin JE1, Roth M.T., Glatt D.M., Gharkholonarehe N., Davidson C.A., Griffin L.M., Esserman D.A., Mumper R.J. The flipped classroom: A course redesign to foster learning and engagement in a health professions school [J]. Academic Medicine, 2014, 89(2): 1-8 